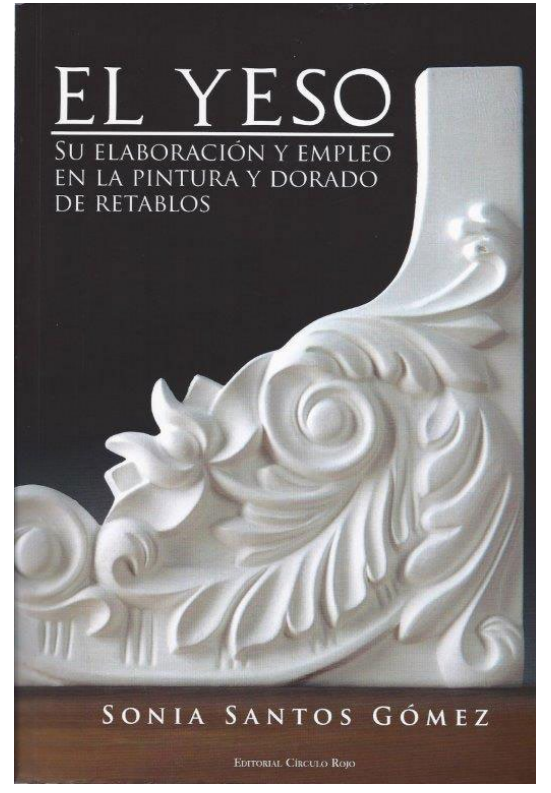

\section{El yeso. Su elaboración y empleo en la pintura y dorado de retablos}

\author{
Sonia Santos Gómez
}

Editorial: Círculo rojo, 2015

Páginas: 328

Idioma: Español

ISBN-13: 978-8490955758
La mayoría de los restauradores estamos familiarizados con un material como el yeso, tan común a lo largo de la historia por sus excelentes cualidades en las preparaciones de la pintura y la escultura policromada sobre madera, y usualmente utilizado en muchos de los tratamientos actuales. No se contaba hasta ahora, sin embargo, con una publicación que reuniera una información tan completa sobre las propiedades físicas y químicas del yeso, sobre los métodos históricos de su elaboración y sobre sus diversas aplicaciones en la pintura y la escultura sobre madera. El Arte de los yesos de Ignacio Gárate, publicado en 1999, podría considerarse un antecedente a destacar; no obstante su enfoque difiere considerablemente en el objeto de interés, en este caso los usos arquitectónicos de este material, con escasas referencias a las técnicas artísticas asociadas a los retablos.

El trabajo de Sonia Santos se basa en una recopilación documental y análisis de textos históricos que aportan descripciones de los procedimientos de elaboración de los yesos y de su aplicación en la preparación de pintura sobre tabla y del dorado bruñido; en una reconstrucción según estos textos de los procedimientos de elaboración de yeso grueso y mate y de los procedimientos de aplicación; y en los análisis mediante técnicas de laboratorio para su caracterización.

Parte de un recorrido histórico sobre la manera en que se ha utilizado el yeso para los aparejos de la pintura sobre tabla y las zonas doradas de los retablos, con una definición de lo que es el yeso y las características mineralógicas del sulfato de calcio en el capítulo II. En el siguiente capítulo describe los métodos tradicionales de fabricación de yeso grueso y yeso mate según los textos antiguos, con una prolija relación y análisis de fuentes bibliográficas y documentales desde la época clásica al siglo XX. El capítulo IV lo dedica a explicar, también según los textos y los documentos históricos, los diferentes procedimientos de aplicación del yeso en la preparación de los soportes de pintura sobre tabla y de las superficies doradas.

Los capítulos $\mathrm{V}$ y $\mathrm{VI}$ se refieren al estudio morfológico y analítico de distintos ejemplos de preparaciones de yeso en ejemplos reales de pintura española, de reconstrucciones de recetas extraídas de los principales textos antiguos, para terminar con el estudio morfológico y analítico de diferentes tipos de yesos mate o "yesos de dorador" disponibles en el comercio.

Por último, finaliza el libro con un capítulo dedicado a la práctica del dorado al agua en el tiempo actual y una extensa y completa bibliografía sobre este tema.

Como profesora del grado de Conservación y Restauración de la Facultad de Bellas Artes de la UCM, Sonia Santos nos proporciona un texto de gran valor didáctico, extensamente documentado y con utilísima información para el conocimiento de los materiales sobre los que debemos intervenir 
como restauradores. Por todo ello esta publicación constituirá sin duda un texto de referencia, tanto en los ámbitos formativos como en la práctica profesional, para el conocimiento de un material, el yeso, cuyas excelentes propiedades lo han convertido en el más usual para los aparejos de los retablos españoles.

\section{Rocío Bruquetas Galán} Museo de América 